\title{
Na Sombra dos Parreirais: condições de trabalho e segurança das mulheres que atuam na produção de uvas finas de mesa no Submédio São Francisco
}

\author{
Sheila Feitosa Santos ${ }^{1}$ \\ Dalila Carla dos Santos ${ }^{2}$
}

\begin{abstract}
RESUMO
O presente artigo busca apresentar as condições de trabalho e segurança do trabalho feminino na produção de uvas finas de mesa no Submédio São Francisco A pesquisa englobou apenas as trabalhadoras que atuam no campo e no packing house, local onde é feita a embalagem das frutas, geralmente realizado por mulheres, por serem consideradas as etapas mais importantes no processo de produção das uvas. Os resultados demonstram que, apesar do Vale São Francisco ser um grande polo de produção e exportação de frutas, as condições de trabalho das mulheres nas fazendas de uva ainda são desfavoráveis. Os resultados demonstram que apesar do Vale São Francisco ser um grande polo de produção e exportação de frutas, as condições de trabalho das mulheres nas fazendas de uva ainda são desfavoráveis. A pesquisa revelou também que a uva é a principal protagonista no cenário da fruticultura irrigada e as trabalhadoras que conciliam as tarefas domésticas desempenhadas no seio familiar (dona de casa, mãe e esposa) e as atividades realizadas nas empresas agroindustriais, aparecem apenas como componentes no plano de fundo da produção e não como verdadeiras protagonistas dessa produção.
\end{abstract}

PALAVRAS-CHAVE: Mulheres. Segurança. Trabalho. Saúde. Parreirais.

\section{In the Shadow of grapevines: working conditions and safety of women working in the production of fine table grapes in Creative Commons License}

\begin{abstract}
This article seeks to present the working conditions and safety of female labor in the production of fine table grapes in the Creative Commons License The research involved only

\footnotetext{
${ }^{1}$ Possui graduação em Comunicação Social - Jornalismo em Multimeios pela Universidade do Estado da Bahia (2016). Produziu como trabalho final de conclusão de curso o documentário Na Sombra dos Parreirais: condições de trabalho das mulheres na produção de uvas finas de mesa no Submédio São Francisco (Juazeiro-BA, Petrolina-PE e lagoa Grande -PE).

2 Doutoranda em Estudos Interdisciplinares sobre Mulheres, Gênero e Feminismo, bolsista CAPES. Possui mestrado em Estudos Interdisciplinares sobre Mulheres, Gênero e Feminismo pela Universidade Federal da Bahia (2012) e graduação em Comunicação Social - Jornalismo em Multimeios pela Universidade do Estado da Bahia (2009). Tem experiência em estudos referentes à Comunicação e Estudos de Gênero, atuando principalmente nos seguintes temas: mulheres, identidade, cinema brasileiro, representação, nordeste e relações de gênero.
} 
the workers who work in the field and packing house, where it is made the packaging of fruit, usually performed by women, because they are considered the most important steps in the grape production process. The results show that despite the San Francisco Valley is a major hub of production and export of fruit, the working conditions of women in grape farms are still unfavorable. The results show that despite the San Francisco Valley is a great pole of production and export of fruit, the working conditions of women in grape farms are still unfavorable. The survey also revealed that the grape is the main protagonist in the scenario of irrigated fruit growing and working to reconcile domestic tasks performed within the family (housewife, mother and wife) and activities in the agro-industrial companies, appear only as components in background of production and not as true protagonists of this production.

KEYWORDS: Women. Safety. Job. Health. Grapevines.

\section{A la sombra de la vid: las condiciones de trabajo y seguridad de las mujeres que trabajan en la producción de uva de mesa finos en Creative Commons License}

\section{RESUMEN}

En este artículo se pretende presentar las condiciones de trabajo y seguridad de trabajo de la mujer en la producción de uva de mesa finos en la licencia Creative Commons La investigación que participan sólo los trabajadores que trabajan en la casa de campo y el embalaje, en donde se hace el envasado de fruta, por lo general realizado por las mujeres, ya que son considerados los pasos más importantes en el proceso de producción de uva. Los resultados muestran que a pesar del Valle de San Francisco es un importante centro de producción y exportación de frutas, las condiciones de trabajo de las mujeres en las explotaciones de uva siguen siendo desfavorables. Los resultados muestran que a pesar del Valle de San Francisco es un gran polo de producción y exportación de frutas, las condiciones de trabajo de las mujeres en las explotaciones de uva siguen siendo desfavorables. La encuesta también reveló que la uva es el protagonista en el escenario de la fruta regada creciendo y trabajando para conciliar las tareas domésticas realizadas dentro de la familia (ama de casa, madre y esposa) y las actividades en las empresas agroindustriales, sólo aparecen como componentes de fondo de la producción y no como verdaderos protagonistas de esta producción.

PALABRAS CLAVE: las mujeres. Seguridad. Trabajo. Salud. Vid.

\section{INTRODUÇÃO}

A região do Vale do São Francisco tem ocupado espaço significativo nos mercados internacionais, devido à produção de frutas para exportação. Um dos grandes destaques da economia regional é a produção de uvas finas de mesa, que são comercializadas tanto no Brasil quanto no exterior para o consumo in natura. A área atual de produção das videiras na região corresponde a aproximadamente 12,2 mil hectares, que favorece a expansão da 
produção de uva e dos seus derivados, como vinhos e sucos. (CODEVASF, 1999 apud SOARES, LEÃO, 2009).

Apesar da fruticultura do Vale do São Francisco proporcionar o desenvolvimento regional, o acesso à produção e aos tipos de atividades que são desempenhadas pelos trabalhadores e trabalhadoras rurais, em especial as mulheres, nos perímetros irrigados, é pequeno. Também existe pouca informação a respeito das condições de vida e trabalho dessas pessoas (OLIVEIRA, 1998).

A luta pelo direto de ser protagonista da sua própria história é um desejo antigo do público feminino, que por muito tempo foram pensadas com base na sua condição biológica de ser mãe e cuidar da família (GROSSI, 1998). As desigualdades existentes entre homens e mulheres, no meio rural ainda é considerado algo aceitável e não um fruto de um processo de repressão, onde as mulheres eram colocadas em situações submissas e este é um assunto que requer muita atenção nas atividades desenvolvidas por mulheres na fruticultura da região (SAFFIOT, 2013).

No caso da produção de uvas finas, essas desigualdades ainda são frequentes. As tarefas consideradas mais pesadas, como por exemplo, a preparação do solo, a aplicação de agrotóxicos, a adubação, são desempenhadas pelos homens. Cabe às mulheres realizar tarefas consideradas, dentro da produção, como mais "leves". De acordo com Oliveira (1998), a escolha pelo público feminino se dá, devido à delicadeza e habilidades das trabalhadoras com as mãos. Assim, é responsabilidade das mulheres ralear $^{3}$ a uva, pentear ${ }^{4}$ e tirar a gavinha ${ }^{5}$, colher e embalar os frutos.

As atividades de ralear, pentear, desbastar são de grande importância no processo produtivo da uva, por ser nestas etapas que se definem a conformação, a beleza e o tamanho do cacho, características que irão influir na sua classificação e, como consequência, no seu preço (OLIVEIRA, 1998, pag. 86).

Uma das tarefas exclusivas das trabalhadoras da uva é o raleio, atividade de folga e retirada de frutas pequenas, que ajuda a dá forma e beleza aos cachos para a comercialização. Por isso, Oliveira (1998) vai reiterar que os trabalhos desempenhados pelas mulheres em fazendas produtoras de uva é uma atividade difícil e de grande responsabilidade, pois qualquer erro pode comprometer a venda do produto. No entanto, por serem consideradas

\footnotetext{
${ }^{3}$ Atividade de desenhar os cachos, geralmente realizada por mulheres.

${ }^{4}$ É uma espécie de poda para renovação dos cachos de uva.

${ }^{5}$ Retirada de uvas podres do cacho.
} 


\section{Revista de Comunicação e Cultura no Semiárido (ComSertões)}

atividades "leves", percebe-se que as funções desempenhadas por tratadas como algo de menor valor.

A presente pesquisa justifica-se por buscar ser um instrumento de divulgação e informação sobre as condições atuais de saúde e segurança do trabalho feminino no campo, além de dar visibilidade à importância do trabalho desempenhado dentro de empresas produtoras de uvas finas de mesa. A pesquisa englobou apenas as trabalhadoras que atuam no campo, com as atividades de desponta, despenca, limpeza, pré-limpeza e colheita e no packing house, local onde é feito a embalagem das frutas, geralmente realizado por mulheres, por serem consideradas as etapas mais importantes no processo de produção e embalagem das uvas.

Para a execução do presente estudo foi utilizado como métodos de averiguação a pesquisa de campo e a observação participativa das condições de trabalho e de vida das artesãs da uva. Também realizou-se o processo de pré-entrevistas para a construção do roteiro de questões e para a elaboração deste, foi realizado processo de perguntas de perguntas semiestruturadas.

\section{AS MULHERES E O TRABALHO RURAL}

Durante muito tempo o patriarcalismo, sistema autoritário e opressor onde as mulheres eram tratadas de forma desigual e submissa, ditava as regras que, segundo o sistema, garantia a felicidade das mulheres. Esse mesmo sistema, de acordo com Saffioti (2013), acreditava que o casamento era o sinônimo de alegria e felicidade do público feminino e por meio dele, as damas alcançavam uma determinada posição social e econômica respeitável, da qual deviam obediência aos maridos, fazendo-lhes tudo o que eles desejassem.

Sardenberg e Macedo (2011) reforçam que as mulheres eram pensadas socialmente como "fêmeas da espécie" e sua vida era definida com base na sua constituição biológica de ser mãe. Dessa forma, a responsabilidade de cuidar da educação dos filhos era exclusivamente delas. Por outro lado, apesar de serem importantes para a economia, elas eram tratadas de forma inferior, quando suas funções eram igualadas a posição jurídica, social e politica do homem. Ainda de acordo com Saffioti (2013), como o nível de produtividade feminino era inferior ao trabalho desempenhado pelo público masculino, não era imposto a estes a possibilidade de exclusão das trabalhadoras da produção, mas o seu desempenho era visto de maneira inferior e totalmente desvalorizado. 
O envolvimento feminino com o trabalho agrícola é antigo e considerado uma das principais formas de emancipação feminina, é o que afirma Koss (2000, apud Biase 2007). Apesar de desempenharem a mesma jornada de trabalho que o público masculino, nas lavouras as camponesas eram vistas apenas como "ajudantes" do marido, pois tinham que, além de realizarem atividades com os maridos, se responsabilizarem pelos afazeres domésticos. Nesse sentido, é importante destacar que, desde o surgimento da agricultura que as mulheres têm contribuído de forma significativa para a produção de alimentos, e que teria sido elas as responsáveis por dá início as tarefas agrícolas no campo.

O desenvolvimento da agricultura só foi possível, depois que a função da semente no desenvolvimento de novas plantas se tornou conhecida. Assim, a introdução de sementes em um determinado espaço da terra, [...] foi o fator determinante da passagem da coleta para o plantio, uma significativa revolução cultural iniciada pelas mulheres. [...] Ao fazerem crescer os produtos da terra, as mulheres associaram a fecundidade à fertilidade. Os estudiosos concordam em atribuir a invenção da agricultura às mulheres. Como coletoras, elas adquiriram um conhecimento dos vegetais, flores e frutos e puderam aprender, pela experiência direta e pela observação contínua, o processo de semeadura e germinação do mundo natural. Passo seguinte, o reproduziram intencionalmente (KOSS, 2000 apud BIASE, 2007, p. 03).

As mulheres eram consideradas seres frágeis, tanto física quanto mentalmente, e cabia a elas apenas a função de ajudantes dos maridos no campo. Não tinham direito a estudar e eram vistas como algo inútil, responsáveis apenas pelos afazeres domésticos. Era levado apenas em consideração a capacidade biológica feminina de gerar descendentes que poderiam ajudar nas atividades no campo (TEDESCHI, 2004). O mesmo autor vai dizer que um dos principais pontos da desigualdade existente entre os gêneros era a educação, uma vez que as moças aprendiam tarefas femininas e os rapazes ações realizadas pelo público masculino. Enquanto os homens eram preparados para competir e comandar, as mulheres aprendiam a cuidar dos familiares, do casamento e do lar.

Tanto no ambiente rural quanto no urbano, as diferenças e hierarquias de gênero sempre persistiram. Dessa forma, os homens eram considerados como os chefes das famílias e as esposas as donas de casa que se preocupavam com os filhos, a organização do lar, além de serem as responsáveis por repassarem para as filhas os ensinamentos de como serem boas donas de casa (PERROT, 2008). Assim, cabiam aos homens as funções consideradas mais pesadas, como cuidar do cultivo, arar a terra. A mão de obra feminina, neste caso, era desvalorizada, e o seu uso era feito apenas como ajuda temporária na produção, sendo 
desconsiderado o fato de após o trabalho na lavoura, estas voltariam para casa, com a obrigação de fazerem, sozinhas, o almoço dos filhos, que estavam ajudando os pais na roça; das filhas que eram prendadas para serem boas esposas; e dos maridos, que por passarem bastante tempo trabalhando, não tinha condições de ajudá-la nas tarefas domésticas.

[...] Na roça, não obstante seja poupada dos trabalhos mais rudes, sua contribuição pode ser igualada a do homem. Ao lado desse trabalho, cujo produto constitui parcela dos meios de subsistência da família, a mulher realiza ainda todos os serviços domésticos, aí incluindo o cuidado de numerosos filhos. Esta situação de sobrecarga da mulher na sociedade sexual e econômica conjugal não lhe confere, entretanto posição de paridade com o marido a não ser a intimidade do lar-longe, portanto, de estranhos (SAFFIOTI, 2013, p. 262).

Para Oliveira (1998), a agricultura se tornará no Brasil, em 1987, uma importante fonte geradora de empregos para a população feminina. Elas vão começar a vender a sua força de trabalho nos períodos de entressafra para grandes e pequenas empresas como forma de contribuir para redução das despesas no lar. Tantos os trabalhadores quanto as trabalhadoras eram chamados para atuar como empregados efetivos ou com contratos temporários, que são chamados de volantes ${ }^{6}$.

Uma das relações de trabalho mais antigas na agricultura é o colonato, atividade que, no século XIX, era utilizada nas fazendas de café no Brasil, como forma de substituir a mão de obra do imigrante europeu. Nesse tipo de serviço, as unidades familiares eram contratadas e o trabalho das mulheres e crianças, que já estavam incluídas nos contratos trabalhistas que exigiam que pelos menos um membro, tivesse idades entre 12 a 15 anos (PRIORE, 2004).

Nas fazendas de café as famílias de colonos tinham que cuidar de uma quantidade da plantação, em troca do sustento da família, além da prestação de outros serviços aos patrões, que poderiam ser remunerados ou não, e em troca, a família teria direito de plantar culturas de subsistência e moradia gratuita.

As mulheres eram obrigadas a enfrentarem, de acordo com Priore (2004), longas e intensas jornadas de trabalho, muitas vezes sozinhas, que geralmente tinha início cedo e encerrava de madrugada.

No espaço da casa, as mulheres continuavam arcando com todo o trabalho doméstico, realizado durante uma jornada extremíssima. Suas vidas, especialmente se mães, resume-se ao trabalho. Levantando-se em geral $4 \mathrm{~h}$ da

\footnotetext{
${ }^{6}$ São diaristas que não tem nenhum vinculo com a empresa que contratou seus serviços.
} 
manhã, preparam a comida para elas e os demais membros da família que trabalham fora e também para os que ficam na casa. Às $6 \mathrm{~h}$ 'pegam' o caminhão para uma jornada de trabalho de nove a dez horas, inclusive aos sábados. Ao chegarem em casa, por volta das $18 \mathrm{~h}$ às $19 \mathrm{~h}$, ainda vão preparar o jantar, lavar roupas, limpar a casa e cuidar dos filhos, podendo receber ajuda de outras mulheres, pois a participação masculina no trabalho doméstico é muito rara. Nunca dormem mais do que seis horas por dia. Aos domingos dedicam-se às tarefas domésticas. Raramente sobram-lhe tempo para o lazer. (PRIORE, 2004, p. 472).

Comparando a rotina de trabalho das mulheres que atuam no campo, atualmente e no packing house das empresas produtoras de uvas do Vale do São Francisco, percebe-se que não se diferenciam da citada por Priore (2004). Geralmente, as trabalhadoras da uva acordam no horário de $3 \mathrm{~h} 30$ e $4 \mathrm{~h}$, fazem o almoço, preparam a marmita, colocam as roupas de trabalho, deixam os lanches e as fardas escolares dos filhos e filhas arrumadas e seguem para sua rotina diária que acontece de segunda a sexta, e em semanas alternadas, de segunda à sábado (OLIVEIRA,1998).

\section{O PROGRESSO DAS MULHERES EM UMA SOCIEDADE MACHISTA}

Uma das principais conquistas femininas foi o acesso a educação, não apenas a doméstica, voltada para o casamento, como a escolarizada. No entanto, a educação feminina era diferente da que era aplicada aos homens, e as mulheres passaram a reivindicar as mesmas condições de ensino dos homens nas escolas, apesar da grande resistência social (SAFFIOTI, 2013).

Outras progressos importantes foram às lutas por direitos essenciais como votar, escolher um parceiro para se relacionar, trabalhar fora dos domicílios e a opção de ter ou não filhos. O direito ao trabalho foi uma conquista importante para as mulheres, mesmo com a resistência social que as colocavam em situações submissas. Elas ainda continuam convivendo com a dupla jornada de trabalho, tornando-se responsáveis por cuidarem sozinhas do lar (SAFFIOTI, 2013). Silveira e Freitas (2007) ainda apontam que, além da dupla jornada de trabalho, as mulheres ainda convivem com o fator da desigualdade entre os sexos no mercado de trabalho e que são marcadas, por exemplo, por diferenças salariais até os dias atuais.

Apesar de ter colocado em xeque a questão do trabalho feminino, a industrialização trouxe mudanças negativas para as mulheres na medida em que elas teriam que se preocupar com a dupla jornada de trabalho: uma em casa e a outra na fábrica. Outros fatores também as 
preocupavam, como a redução de salários. Os trabalhadores, de acordo com Perrot (2008), tinham medo da concorrência feminina e defendiam a ideia de que os homens deviam ser os responsáveis pelo sustento familiar e as mulheres ficavam responsáveis por cuidar da educação dos filhos.

A inserção das mulheres no mercado de trabalho infelizmente não alterou a situação de desigualdade entre os sexos, na verdade acabou deixando-a mais evidente, como explica Silveira e Freitas (2007).

As condições de inferioridade das mulheres são evidenciadas no contexto social: é alta a taxa de desemprego em trabalhos precários; recebem salários mais baixos que os dos homens, mesmos com níveis de escolaridade mais elevados (IBGE). Ocupam poucos postos de chefia e de supervisão; cumprem uma jornada de trabalho maior, uma vez que conciliam o trabalho doméstico com o profissional (SILVEIRA, FREITAS 2007, p. 16).

Segundo Hirata (apud SILVEIRA E FREITAS, 2007), mesmo com o aumento do número de mulheres na década de 1980 em altos postos de trabalhos nos escritórios, elas ainda não tinham parte dos seus direitos garantidos, pois era negado a elas o acesso aos planos de carreira e assinavam contratos temporários que não lhes davam garantias trabalhistas. Dessa forma, o sistema econômico vigente será o responsável por delinear os espaços existentes no mercado de trabalho e as atividades desempenhadas e as mulheres vão buscar se adaptar a essa situação.

No Brasil, na década de 1980, aconteceram mudanças no que diz respeito à ocupação de postos de trabalhos entre homens e mulheres. Estudos realizados por Bruschini (apud SILVEIRA E FREITAS, 2007) afirmam que, durante a década de 1980 e 1990, as trabalhadoras conquistam um grau maior de instrução e conhecimento. Em alguns setores esse fator possibilitou o aumento do reconhecimento das tarefas desempenhadas por mulheres no mercado do trabalho, remunerações mais altas que permitiram a saída das mulheres da dupla jornada de trabalho, uma vez que elas tinham a possibilidade de pagar outras mulheres para ficar responsável pelos afazeres do lar.

\section{QUEM SÃO AS TRABALHADORAS DA UVA DO VALE DO SÃO FRANCISCO?}




\section{Revista de Comunicação e Cultura no Semiárido (ComSertões)}

No Submédio São Francisco, o quantitativo de mulheres atuando na fruticultura da região, com serviços de forma fixa ou temporária, é superior ao número de homens nesta atividade, chegando a $60 \%$ da força de produção, de acordo com estudos realizados por Branco e Vainsencher (apud SILVEIRA e FREITAS, 2007). As trabalhadoras que atuam na produção de uvas finas têm importância fundamental no processo de produção e comercialização. Mesmo que algumas atividades desempenhadas por elas sejam consideradas complicadas e de grande importância para a comercialização dos produtos, suas tarefas ainda são vistas como inferiores, quando comparadas, as que estão sendo realizada pelo público masculino (SILVEIRA E FREITAS 2007).

De acordo com estudos realizados por Cunha (2006 apud SILVEIRA e FREITAS 2007), a força de trabalho feminina no trato com a uva é utilizada em atividades como a despenca, despontamento de ramos, limpeza, pré-limpeza, raleio, colheita, seleção e embalagem dos frutos que são realizadas no período de entressafra. Com base nisso, suas atividades, ainda segundo esse autor, não são legalmente reconhecidas e por serem consideradas tarefas de fácil manejo, muitas empresas não oferecem treinamentos para esses fins. A força de trabalhado feminina, como já citado, será visto apenas como uma ajuda, que seria utilizada quando o trabalho desempenhado pelos maridos não contemplasse a produção. (CUNHA apud SIL VEIRA e FREITAS 2007).

Segundo os estudos realizados por Josefa Cavalcanti (1996), a produção de uvas finas de mesa para mercados internacionais deve seguir as exigências definidas pelas empresas e países compradores, relacionados às condições ambientais e tecnológicas, que dizem respeito ao tempo de produção, entrega e armazenamento da mercadoria, assegurando assim a qualidade das uvas comercializadas. Cavalcanti (1997) ainda explica que atender as exigências do mercado, com a introdução de novos recursos tecnológicos na viticultura, significa reduzir/substituir a mão de obra existente por outra mais qualificada, e esse fator pode atingir diretamente as mulheres, que ocupam cargos significativos dentro da produção, com a realização de trabalhos manuais.

Essas inovações tecnológicas permitem a redução do tempo gasto na realização das atividades, enquanto são favoráveis à produção agrícola pelas razões já mencionadas, mas trazem também problemas para a região em relação à redução de postos de trabalho que acabam por eclipsar o pretendido e em certa medida alcançado desenvolvimento social da área, que ao longo dos anos tornou-se pólo atrativo para os trabalhadores da terra pelo grande número de empregos gerados com a implantação e subsequente desenvolvimento da agricultura irrigada, ao tempo em que redefinem a 
posição das mulheres no mercado de trabalho. (CAVALCANTI, 1997, p. 279).

É importante observar que nos trabalhos realizados por Cavalcanti (1996), (1997) e Oliveira (1998) pode-se analisar que, apesar do quantitativo de vendas de uvas no país e no exterior, o trabalho que é desempenhado pelas mulheres nas empresas é pouco valorizado e até mesmo invisível para o público que consome a uva.

Dentro das empresas produtoras de frutas do Vale do São Francisco, segundo Branco e Vainsencher (apud SILVEIRA E FREITAS, 2007) existem dois tipos de acordo: o trabalho assalariado onde elas têm seus direitos garantidos por lei e o contrato temporário, em que as trabalhadoras serão chamadas de diaristas e não têm nenhuma estabilidade, recebendo apenas o salário individual, sem nenhuma garantia. As trabalhadoras mais idosas também serão contratadas como diaristas, sob a alegação de que elas têm mais experiências no trabalho que vão desempenhar.

Nos períodos de colheitas existem irregularidades na contratação de trabalhadores e trabalhadoras. O contrato de mão de obra temporária para desempenho de atividades como poda, raleio e colheita aumenta, chegando a superar o número de trabalhadores permanentes (BRANCO apud CAVALCANTI, 1997). Por outro lado, quando não há grandes colheitas, as trabalhadoras efetivas são levadas a fazerem um revezamento de atividades que acontece de acordo com a necessidade da empresa naquele período. Segundo relatos das próprias trabalhadoras, elas podem desempenhar tarefas como a pré-limpeza um certo dia e no outro, por exemplo, ir trabalhar no packing house, embalando a uva.

As trabalhadores realizam algumas atividades especificas, entre elas está a observação das características do cacho da uva. Antes do trabalho de embalagem das frutas, são retiradas as bagas e gavinhas danificadas do cacho para que depois sejam depositadas nos contentores. Após esse trabalho, as frutas serão levadas para o Packing House, onde os cachos serão selecionados, de acordo com o tamanho, e colocados em recipientes plásticos (cumbucas). Após esse processo, a uva será embalada em caixas de papelão e levadas para salas de préresfriamento, com o objetivo de fazer com que elas percam calor adquirido no campo, antes que sejam transportadas para longas distâncias (SOARES e LEÃO, 2009).

Segundo os estudos realizados por Oliveira (1998), existe nas empresas uma divisão evidente entre os trabalhos desempenhados por homens e mulheres. Por serem consideradas habilidosas e delicadas, cabe às mulheres, atualmente, a função de fazer o raleio da uva, pentear, colher e embalar as frutas no Packing House. A autora ainda vai destacar que essas 
tarefas são consideradas de extrema importância na hora de comercializar o produto, pois dependem delas a beleza e formação dos cachos de uva.

A desvalorização das tarefas desempenhadas pelas mulheres dentro do ambiente de trabalho pode ser justificada pela supervalorização da força física do homem, é o que explica Saffioti (2013). Ela ainda vai reforçar que por outro lado, quando o homem passar a realizar atividades consideradas "leves", como no caso do raleio e limpeza da uva, essa justificativa se torna vulnerável.

\section{PROCESSO METODOLÓGICO}

Para a concretização da presente pesquisa, foi realizada uma revisão bibliográfica com o objetivo de entender o panorama a cerca do trabalho das mulheres na produção de uvas finas de mesa do Vale do São Francisco.

Durante a investigação, foi feita a pesquisa de cunho qualitativo, que, de acordo com Mirian Goldenberg (2004), consiste em um tipo de abordagem em que o pesquisador não defende apenas um único método de investigação dentro das ciências sociais e "não pode fazer julgamentos nem permitir que seus preconceitos e crenças contaminem a pesquisa" (p. 17). A pesquisa realizada com base em dados qualitativos, como reforça Goldenberg (2004), é feita por meio de descrições das vivências dos indivíduos envolvidos na investigação, com o objetivo de compreender o universo que o cerca. Dessa forma, o pesquisador terá acesso a essas vivências, ou seja, o universo do entrevistado, por meio dos olhares e percepções dos pesquisados. Também foi realizada a pesquisa de campo, que segundo Marconi (1990):

Consiste na observação de fatos e fenômenos tal como ocorrem espontaneamente, na coleta de dados a eles referentes e no registro de variáveis que presume relevantes, para analisa-los. A pesquisa de campo propriamente dite 'não deve ser confundida com uma simples coleta de dados (este último corresponde à segunda fase de qualquer pesquisa); é algo mais que isso, pois exige contar com controles adequados e com objetivos preestabelecidos que discriminam suficientemente o que deve ser coletado' (TRUJILO, 1982 apud MARCONI e LAKATOS, 1990, p.75).

Utilizou-se também como técnica, a entrevista semi-estruturada ou individual, que é vista como uma técnica de coleta de dados qualitativos que se apoia em questionamentos 
ancorados em hipóteses que podem beneficiar o pesquisador e o tema que será analisado (TRIVINOS apud DUARTE, 2006). Nesse tipo de entrevista, o pesquisador elabora questionamentos com o objetivo de alcançar resultados do tema investigado. Também é função do entrevistador fazer interferências, elaborando novas questões e levantando hipóteses durante a execução da investigação empírica. Para Robert Farr (apud BAUER e GASKELL, 2002) as entrevistas qualitativas são "essencialmente uma técnica ou método para estabelecer ou descobrir que existem perspectivas, ou pontos de vistas sobre os fatos além daqueles da pessoa que inicia a entrevista” (p.65). No caso deste estudo, essas entrevistas foram realizadas com trabalhadoras das cidades de Juazeiro-BA, Petrolina-PE e Lagoa Grande-PE que atuam em empresas produtoras de uvas para exportação. Os questionamentos foram realizados com seis personagens, que falaram sobre as condições de segurança nos parreirais.

\section{RESULTADOS AVALIADOS}

Observou-se, durante a realização da presente pesquisa que, apesar de desempenharem trabalhos importantes para a empresa, as tarefas femininas ainda são desvalorizadas. Um estudo realizado por Bloch (1996) revelou que nesse período, as trabalhadoras sofriam com intoxicação causada por agrotóxico. Em 2016 a situação não mudou e ainda existem casos negligenciados pelas empresas. Uma das questões alegadas pelo Sindicato dos Trabalhadores Rurais de Juazeiro (STR) é a difícil comprovação do problema. Muitas fazendas se recusam a indenizar as trabalhadoras e por medo de perder o emprego, muitas retornam para debaixo dos parreirais. Muitas empresas ainda não dispõe de Equipamentos de Proteção Individual (EPIS), como relatou a trabalhadora F.N.D (2016):

\footnotetext{
"Não tem EPI, não tem bota, não tem óculos, não tem luva... É um estado de calamidade! Lá é dando veneno com a gente dentro. Se não for eu para tirar as trabalhadoras eles não estão nem ai. É a gente trabalhando aqui e o veneno passando aqui do lado. Ai eu vou perguntar e eles dizem que não é veneno".
}

Em sua pesquisa, Bloch (1996) vai dizer que muitas trabalhadoras, que atuam no raleio e na colheita da uva afirmavam sentir tonturas, problemas de pressão alta e coceiras pelo corpo, após entrarem nas áreas pulverizadas, situação que ainda permanece nos dias atuais. Segundo a trabalhadora G. S. S. M, as mulheres grávidas realizam as mesmas atividades das não gestantes e muitas empresas não remanejam elas para outros cargos. 


\section{Revista de Comunicação e Cultura no Semiárido (ComSertões)}

De acordo com as trabalhadoras de uma empresa de Petrolina (PE), quando há intoxicação por agrotóxico, muitas empresas se recusam a indenizar as vítimas e até mesmo comprovar que usou o produto. É o que explica a trabalhadora L.A.D que se intoxicou com agrotóxico e a empresa em que trabalhou em Juazeiro não a indenizou. Ela teve $80 \%$ do corpo queimado, devido a uma alergia causada por um agrotóxico chamado Dormex ${ }^{7}$. A trabalhadora relatou também que a empresa se recusou a afirmar que tinha aplicado o agrotóxico no local onde ela sofreu o dano. Apesar de passar um ano se recuperando, a empresa afastou a trabalhadora por apenas quatro meses e não pagou nenhum medicamento usado do tratamento da paciente.

Algumas trabalhadoras relatam também que não gostam das atividades que desempenham. Explicam que são muito cansativas e que realizam aquela rotina diária por causa dos filhos. "Não gosto do que faço. É um trabalho muito desgastante. Todo dia pegando sol quente, chego em casa com a cabeça doendo. Mas, preciso do dinheiro, não tenho estudo. Não posso sair”. (M.G.P, 2016).

Outra queixa frequente dos trabalhadores, no passado, era a circulação de transportes seguros. De acordo com Bloch (1996), as maiores reclamações eram voltadas para os atrasos, a superlotação e a falta de segurança nos carros que levavam os trabalhares e trabalhadoras para a empresa. No período em que foi realizada a pesquisa, na década de 1990, os peões iam para as fazendas na carroceria de caminhões, conhecidos como "pau de arara" e inúmeros acidentes aconteciam. Com isso, os Sindicatos de Trabalhadores Rurais passaram a lutar por condições melhores de segurança e as empresas de Juazeiro (BA), Petrolina (PE) e Lagoa Grande (PE) substituíram os veículos antigos por ônibus e essas mudanças foram alcançadas graças a Convenção Coletiva do Trabalho, unificada Bahia e Pernambuco. Por outro lado, ainda existem outras carências. Algumas empresas ainda não dispõem de enfermaria ou médicos de plantão em casos de acidentes.

"Mas em relação as pessoas adoecerem, você sabe que em toda empresa, todo mundo adoece, uma hora ou outra. Eu mesmo estou com problema de nervo. Semana passada eu desmaiei, ninguém me acudiu. Fiquei lá... não tem nenhum álcool para passar na gente. E o gerente, segundo eu fiquei sabendo, porque ele não falou para mim, ele falou que se pudesse dar veneno as trabalhadoras e ele dava. Lá não tem transporte. Eles simplesmente me colocaram em cima de uma moto e me levaram para o posto" (FND, 2016).

\footnotetext{
${ }^{7}$ Produto químico usado para acelerar o crescimento dos brotos nos parreiras de uva, após a realização da poda.
} 
As mulheres também sofrem assédio moral e sexual dentro dos locais de trabalho. Os maiores insultos geralmente são feitos com delegadas sindicais, que por conhecerem os seus direitos, não tem medo de representar as trabalhadoras e muito menos buscar suas garantias. O assédio sexual também é uma questão que, comumente é encontrada nos parreirais de uva e, muitas vezes, as trabalhadoras se recusam a procurar os sindicatos para realizarem as denúncias, com medo de retaliação e perseguição, que pode ocasionar a perca do emprego.

\footnotetext{
"Ai depois veio os outros assédios. Ele me ofereceu dinheiro para sair com ele, não só a mim como a outras pessoas também, ele ofereceu, um monte de funcionárias lá dentro da empresa. Ele dizia que eu tinha caso com todo rapaz que eu conversasse na empresa que até mesmo o pessoal do sindicato estava tendo caso comigo, por conta disso por que ele acha que as pessoas só porque é mulher, só porque é pobre, tem que ter caso com pessoas que tem dinheiro e eu acho isso um absurdo". (FND, 2016)
}

Outra questão voltada para a saúde dos trabalhadores e trabalhadoras era a ausência de água potável nas empresas. Bloch (1996) vai dizer que a água fornecida aos trabalhadores não recebia tratamento algum.. Em alguns locais a situação ainda era pior. Os peões só tinham acesso à água da irrigação, que fica concentrada em canais, que levavam água até os parreirais, muitas vezes cheios de substâncias químicas. Em alguns locais percebe-se que a situação mudou. Existem empresas que dispõe de bebedouros com água gelada e potável para as trabalhadoras e de locais onde a comida possa ser esquentada. $\mathrm{Na}$ maioria dos casos, as trabalhadoras comem boia-fria.

\section{CONSIDERAÇÕES FINAIS}

É importante ressaltar que apesar dos avanços conquistados pela Consolidação das Leis do Trabalho (CLT) e da Convenção Coletiva do Trabalho, no que diz respeito ao uso de Equipamentos de Proteção Individual (EPIS), assistência médica, sinalização de segurança, água potável, entre outros direitos. Existem empresas que descumprem essas obrigações e ainda vivem a realidade retratada, há vinte anos, por Bloch (1996) onde não existia o acesso a direitos essenciais no trabalho como atendimento médico, transportes seguros, difícil comprovação em casos de intoxicação por agrotóxico, a entrada irregular em áreas pulverizadas. 


\section{Revista de Comunicação e Cultura no Semiárido (ComSertões)}

Sobre a ação dos Sindicatos dos Trabalhadores Rurais (STR) percebe-se que apesar da fiscalização efetiva nos locais, as trabalhadoras ainda têm receio de fazer denúncias e muitas vezes só recorrem ao STR quando a situação está agravada. Também não há, nesses locais discussões relacionadas às mulheres dentro do sindicado, que historicamente, acaba sendo ocupado por homens. Observou-se também que muitas trabalhadoras não possuem a noção da importância do seu trabalho e, principalmente, os riscos que esse pode trazer para a saúde humana. Também comprovamos que as mulheres ainda convivem com a dupla e até tripla jornada de trabalho, mas algumas delas contam com a ajuda dos maridos, que também trabalham na fruticultura da região, situações semelhantes às retratadas por Oliveira (1998).

Conclui-se que apesar do Vale do São Francisco ser um grande polo de produção de frutas, comercializadas tanto no Brasil quanto o exterior, como afirma Cavalcanti (1997), as condições de trabalho das mulheres ainda não são favoráveis, em boa parte das fazendas em que a presente pesquisa foi realizada, em especial as que exportam frutas. É importante frisar que em alguns locais são respeitadas a legislação trabalhista, mas na maioria dos casos, as empresas não oferecem as condições mínimas necessárias para o exercício das atividades durante o processo de limpeza e colheita da uva.

\section{REFERÊNCIAS}

BAUER, Martin W. GASKELL, George. Pesquisa qualitativa com texto, som e imagem. Rio de Janeiro. Vozes, 2002.

BIASE, Laura de. A condição feminina na agricultura e a viabilidade da agroecologia. Disponível em: http:/www.revistas.usp.br/agraria/article/view/128/128. Acessado em: 14 de set de 2015.

BLOCH, Didier. As frutas amargas do Velho Chico: irrigação e desenvolvimento no Vale do São Francisco. São Paulo. Livros da Terra, 1996.

CAVALCANTI, Josefa Salete Barbosa. ANDRADE, BerlanoBênis França de. RODRIGUES, Victor. Mulheres e trabalho na agricultura de exportação: questões atuais.

Disponível em: http://www.revista.ufpe.br/revistaanthropologicas/index.php/revista/article/view/245 . Acesso em: 29 de mar de 2015.

CAVALCANTI, Josefa Salete Barbosa . Globalização, estratégia produtivas e trabalho de homens e mulheres na fruticultura de exportação: o caso do Vale do São Francisco. Disponível em: bibliotecavirtual.clacso.org.ar/ar/libros/brasil/nabuco/glob.doc. Acesso em 29 de mar de 2015. 
_. Frutas para o mercado global. Disponível em: http://www.scielo.br/scielo.php?script=sci_arttext\&pid=S0103-40141997000100005. Acessado em: 20 de mar de 2015.

GOLDENBERG, Mirian. Arte de Pesquisar. Rio de Janeiro. Editora Record. 2004.

GROSSI, Miriam Pillar. Identidade de gênero e sexualidade. Antropologia em $1^{\text {a }}$ mão.Florianópolis, UFSC/ PPGAS,1998.

MARCONI, Marina de Andrade. LAKATOS, Eva Maria. Técnicas de pesquisa: planejamento e execução de pesquisas, amostragem e técnicas de pesquisa e elaboração, análise e interpretação de dados. Atlas. São Paulo, 1990.

OLIVEIRA, Lúcia Marisy Souza Ribeiro de. Dois anos em um: a realidade do cotidiano feminino. Salvador. Egba, 1998.

PERROT, Michele. Minha história das mulheres. São Paulo. Editora Contexto. 2008.

PRIORI, Mary Del (ORG). História das mulheres no Brasil. São Paulo, SP. Editora Pinsky, 2004.

SAFFIOTI, Heleieth Iara Bongiovani. A mulher na sociedade de classes: mito e realidade. São Paulo-SP. Expressão popular, 2013.

SANDEMBERG, Cecília M. B. MACEDO S. Márcia. RELAÇÕES DE GÊNERO: uma breve introdução ao tema In. COSTA, Ana Alice Alcântara. LOLE, Alexnaldo Teixeira. VANIN, Macedo (ORG). Ensino e gênero: Perspectivas Transversais . Salvador: UFBANEIM, 2011, p 33-46.

SILVEIRA, Maria Lúcia. FREITAS, Taís Viudes. Trabalho, corpo e vida das mulheres crítica à sociedade de mercado. São Paulo. SOF, 2007.

TEDESCHI, Losandro Antônio. MEU NOME É "AJUDA".A vida cotidiana e as relações de poder, gênero e trabalho das mulheres trabalhadoras rurais na Região Noroeste do Rio Grande do Sul. Disponível em: https://revistas.unijui.edu.br/index.php/contextoeducacao/article/viewFile/1 132/887.

Acessado em: 04 de abr de 2015. 